\title{
A GEOPHYSICAL SURVEY \\ IN THE ARCHAEOLOGICAL SITE OF ARCHONTIKO, YANNITSA.
}

\section{A. SAVVAIDIS ${ }^{1}$, G. TSOKAS ${ }^{1}$, P. TSOURLOS ${ }^{1}$, G. VARGEMEZIS ${ }^{1}$, A. CHRYSOSTOMOU ${ }^{2}$ AND P.CRYSOSTOMOU ${ }^{2}$}

\begin{abstract}
The present case history comprises the investigation of the archaeological site in the area of Archontiko employing measurements of the total magnetic field variations. Two data sets were collected in 1992 and 1993 in order to map the area of interest.

The field data were corrected for diurnal variations. Processing of the data involved estimating statistical parameters, which allowed the unification of the single data blocks of $20 \mathrm{~m}$ x $20 \mathrm{~m}$ into two main blocks containing the data surveyed in 1992 and 1993. Inverse filtering was next applied to parts of the processed data set, which involved geophysical anomalies of particular interest. The followed excavations confirmed the results of the geophysical survey, validating that the magnetic method is reasonably one of the most popular in prospecting archaeological sites.
\end{abstract}

KEY WORDS: Archaeological Prospecting, Magnetic, Inverse Filtering, Archontiko.

\section{INTRODUCTION}

The ancient settlement of Archontiko is $4.5 \mathrm{~km} \mathrm{NW}$ of ancient Pella in North Greece (Figure 1). The findings showed that the area was first occupied by the end of the Iron Age, i.e. $650-550$ B.C. Also, showed that the topographic table of Archontiko was a major settlement of the Yannitsa province due to its concessive position by the main roads of Macedonia (Chrysostomou A. and Chrysostomou P., 1993). At the upper layers of the ruins, findings of the Roman and Byzantine times were also unearthed.

The geophysical methods have been used in order to detect and map antiquities in various sites in Greece (e.g., Tsokas et al., 1994; 1995; Savvaidis et al., 1999). The resistivity mapping employing the twin probe array, the total magnetic field variations, the airborne photos and the Ground Probing Radar are the most popular methods in this respect. However, almost all geophysical methods can be used to tackle specific problems.

From 1992 till 1994, many geophysical surveys were carried out in the area of Archontiko to collect mainly magnetic data. Resistivity measurements were also conducted in a small part of the area. The data presented in this study cover the northern side of the topographic table of Archontiko and they were collected during two campaigns during the summer of the years 1992 and 1993 (Figure 2).

\section{PROCESSING}

The data were collected using the SCINTREX proton precession magnetometers. They were reduced for the diurnal variation of the magnetic field using the records of a base station operating simultaneously in the area. The area was subdivided into grids of $10 \times 10 \mathrm{~m}^{2}$ and $20 \times 20 \mathrm{~m}^{2}$ and measurement were taken along profiles spaced $1 \mathrm{~m}$ apart stepwise in $1 \mathrm{~m}$ intervals. At first, two grids were established, one for each period (1992 and 1993). In Figure 3, the data of 1992 (NW) and 1993 (NE) are presented into two unified grids with different gray scales for the values of the total magnetic field.

In order to enhance the view of the magnetic anomalies, the data were further processed using the software library of Philips (1997). A median filter of $3 \times 3$ points was applied to each original sub-grid, in order to eliminate the erratic spikes.

Next, statistical values were calculated for each grid that include, the mean value of the total magnetic field, the RMS and the standard deviation. For each data set (1992 and 1993), one grid was selected which served as the base for the integration of each set. The criteria for the selection of the base grid were its mean value to be

1. Geophysical Laboratory, Dept. of Geology, Aristotele University of Thessaloniki, GR 54006, Thessaloniki, Greece.

2. IZ' Ephoria of Prehistoric and Classic Antiquities, Pella,Greece. 


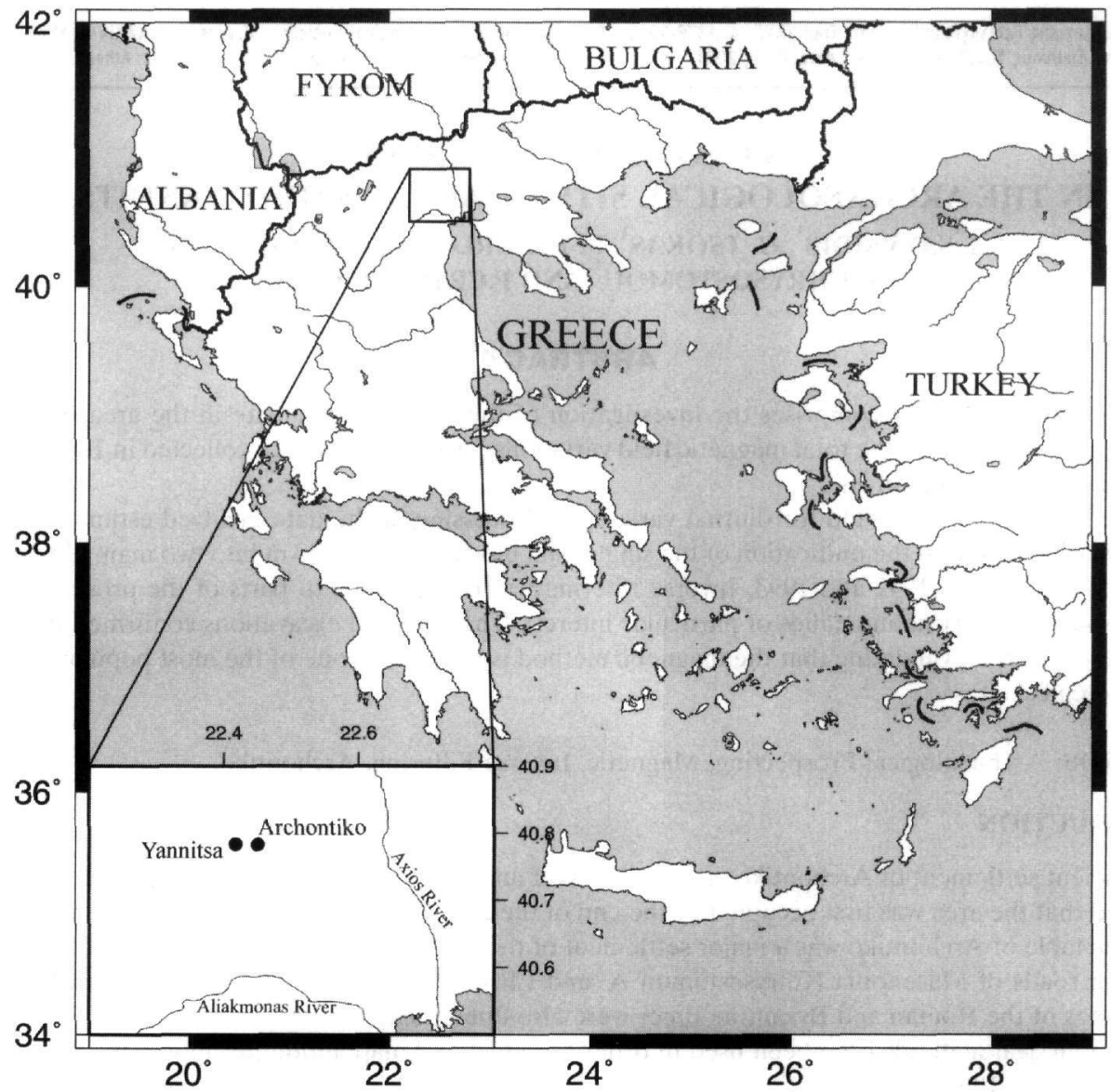

Figure 1. The position of Archontiko and Yannitsa. They are located between the rivers Axios and Aliakmonas.

close to the mean value of all the data in the set and also to have the smallest RMS and standard deviation. For the data set of 1992 the mean value of all data is -20.729 . The grid selected as the base grid has a mean value of -20.61 , RMS equal to 22.80 , which is one of the lowest and a standard deviation of 9.77 , that is the second lowest. For the data set of 1993 the mean value of all data is 259.72 . The grid selected as base has a mean value of 259.4, RMS equal of 259.51 , and a standard deviation of 7.77 , that is the lowest.

After the selection of the base grids, the difference of the mean value of each grid from the base one was calculated. Subsequently, these values were added to each sub-grid and an integrated grid was formed for each data set. In Figure 4 the data after the median filter and mean value corrections applied are presented. The most clearly shown features correspond to, an elongated anomaly on the west side (a), a parallelogram like anomaly (b) in the 1992 data set, and two anomalies one of high (c) and one of low (d) magnitude of the magnetic field in the data set of 1993 .

\section{INVERSE FILTERING}

Two-dimensional inversion filtering (Tsokas and Papazachos, 1992) was applied to blocks A and B of the data. The process is based on the construction of the least-squares filter created by a rectangular model. The idea is to filter the magnetic response of the body in order to delineate its extend and shape.

A 7-point inverse filter was computed by inverting the effect produced by a vertical sided $0.5 \times 0.5 \times 0.5 \mathrm{~m}$ prism buried at a depth of $0.5 \mathrm{~m}$ assuming only the existence of induced magnetization.

The produced filter was convolved with parts of the smoothed magnetic data for two areas designated as blocks A and B (Figure 2). The original data and filtered results for blocks A and B are depicted in figures 5, and 7 respectively.

As it is evident on Figure 5, the filtering operation sharpened the lateral extent of the anomaly caused by the 


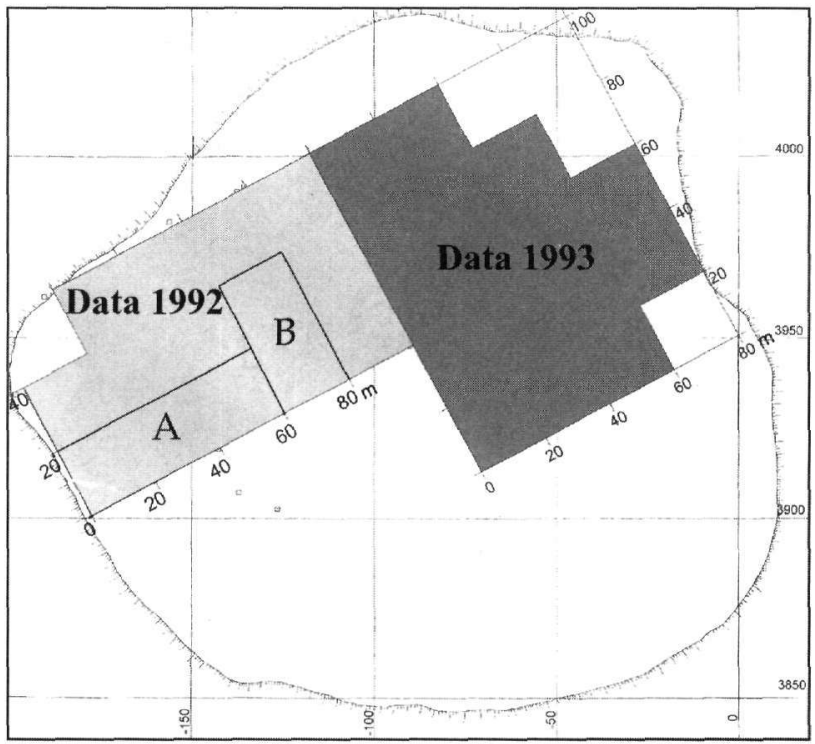

Figure 2. The blocks that constitute the surveyed area. Data sets of 1992 and 1993 are marked separately. Smaller blocks $A$ and $B$ denote the area where the inverse filtering technique was applied.

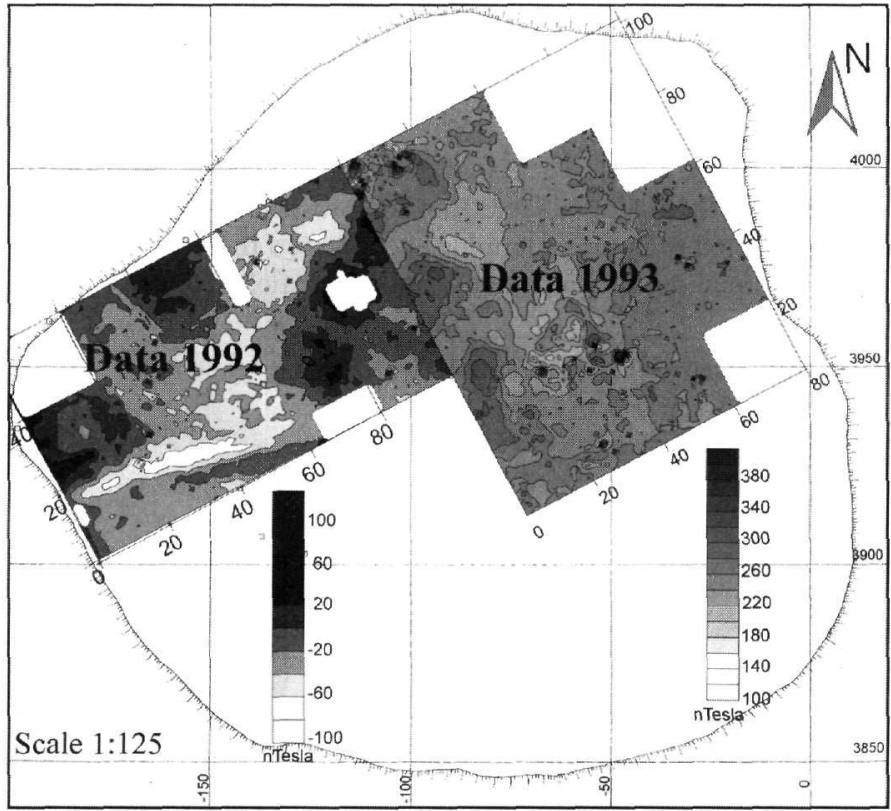

Figure 3. The distribution of the total magnetic field for the datasets of 1992 (NW) and 1993 (NE).

elongated feature. In fact, the new signature gives an estimate of the real width of the buried body. It can be now inferred by simple inspection of Figure 5 that the body must be about $1 \mathrm{~m}$ wide. After the excavations took place in block $A$ the inner-wall was revealed as shown in Figure 6 . The elongated feature mapped by the magnetic data corresponds to the inner wall.

In Figure 7 the positive magnetic anomaly has been replaced and reduced to its real location.

Using the inversion filtering to selected anomalies proves particular useful to obtain further information about the prospected features. 


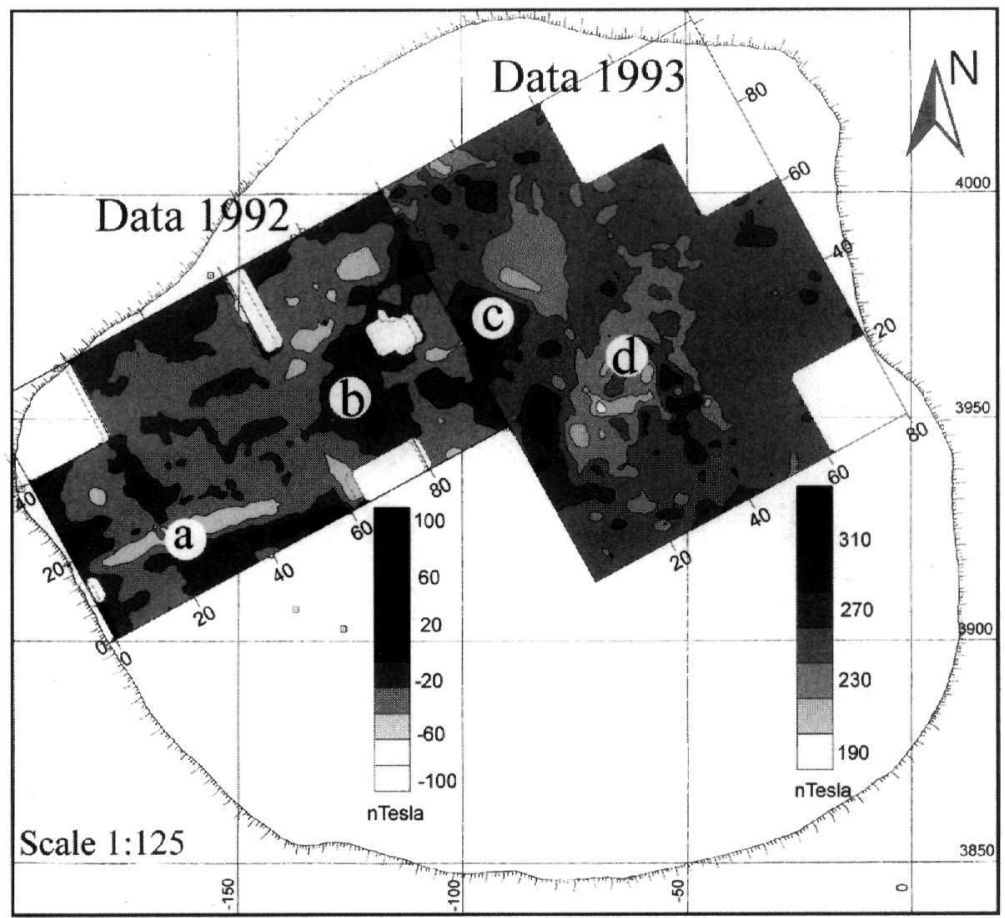

Figure 4. Data after the median filter and the mean value corrections.

\section{CONCLUSIONS}

The use of the magnetic method is a valuable tool for prospecting archaeological sites, since delineates successfully a wide range of buried features commonly encountered there.

The structures are well defined by mapping the total magnetic field. However, further processing of the raw

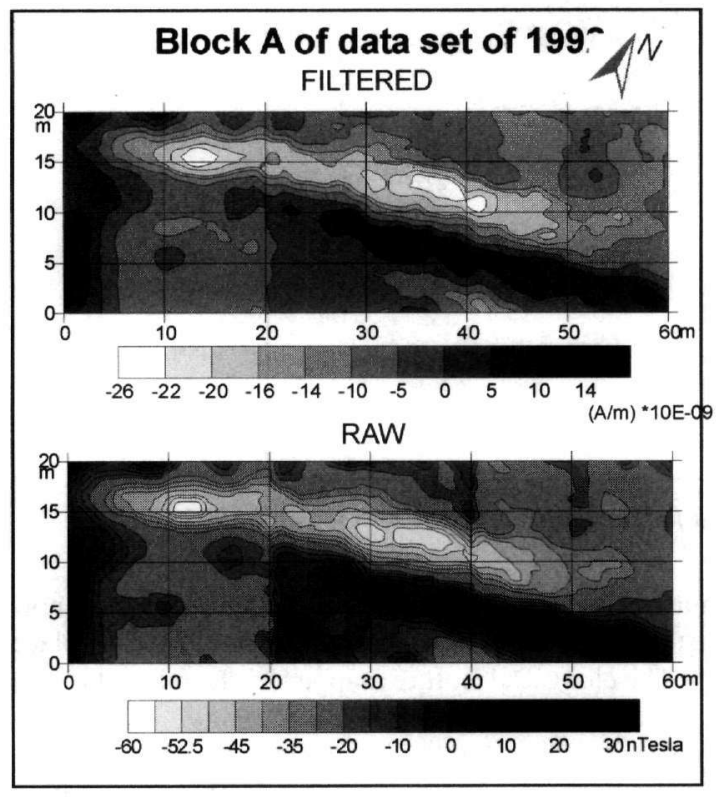

Figure 5. Raw and filtered data of block $A$.

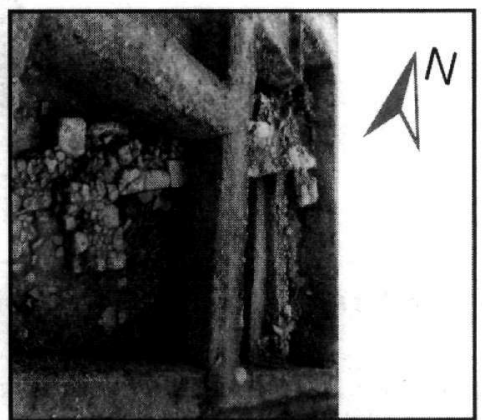

Figure 6. Excavation that show the unearthed foundations of an inner wall. This structure, along with its fallen towards north upper structure produced the linear anomaly observed in the Southwest of the surveyed area. 


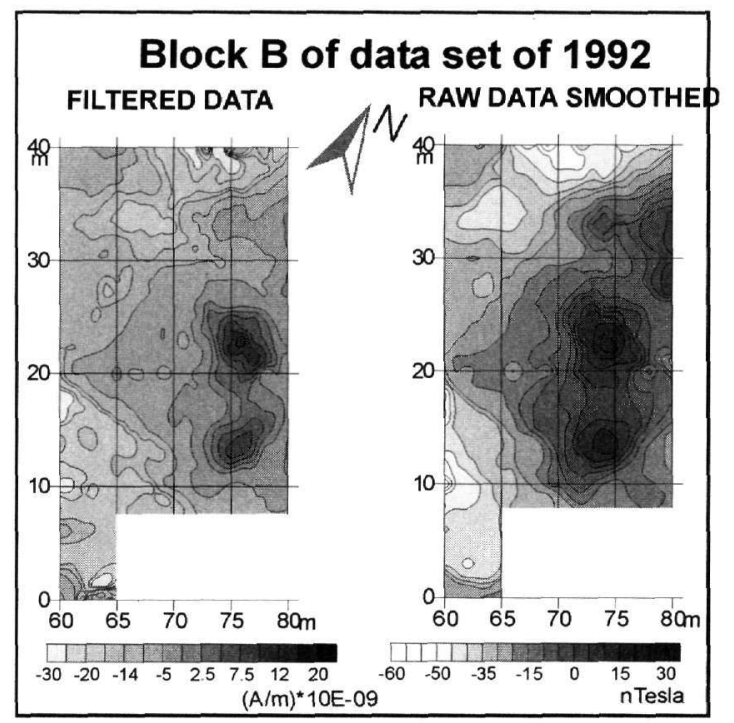

Figure 7. Raw and filtered data of block $B$.

data, using the inverse filtering technique, resulted into the delineation of the distribution of the subsurface magnetization, giving a better image of the lay out and the lateral dimensions of the concealed ruins. By definition the inverse filter outcome (Tsokas and Papazachos, 1992) is the distribution of the magnetization provided that only induced type of magnetization is present. Consequently, if the values are divided by the normal field strength they yield the susceptibility mapping of the area. The inverse filtering method revealed properties of the buried targets (lateral extent and magnetization) and produced a picture of their plane view. It has to be stressed that the geophysical interpretation results fit remarkably well with the findings of the archaeological excavation.

The modern processing techniques enhance the effectiveness of the magnetic prospecting in areas of complex structure.

\section{REFERENCE}

CHRYSOSTOMOU A. AND CHRYSOSTOMOU P., 1993, 'Excavation of the table at Archontiko, Yannitsa, in

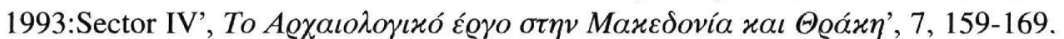

PHILIPS D. J., 1997, 'Potential-Field Geophysical Software for the PC, version 2.2', USGS, Open-File Report, 97-725, 25pp.

SAVVAIDIS A., TSOKAS G., LIRITZIS. Y AND APOSTOLOU M., 1999, 'The Location and Mapping of Ancient Ruins on the Castle of Lefkas (Greece) by Resistivity and GPR Methods', Archaeological Prospection, 6, 63-73.

TSOKAS G.N. AND PAPAZACHOS C.B., 1992, 'Two-dimensional inversion filters in magnetic prospecting: Application to the exploration for buried antiquities', Geophysics, 57, 8, 1004-1013.

TSOKAS G.N., GIANNOPOULOS A., TSOURLOS P., VARGEMEZIS G., TEALBY J.M., SARRIS A., PAPAZACHOS C.B. AND SAVOPOULOU T., 1994, 'A large scale geophysical survey in the archaeological site of Europos (northern Greece)', Journal of Applied Geophysics, 32, 85-98.

TSOKAS G.N., PAPAZACHOS C.B., VAFIDIS A., LOUKOYIANNAKIS M.Z., VARGEMEZIS G. AND TZIMEAS K., 1995, 'The detection of monumental tombs in tumuli by refraction seismics', Geophysics, 60 , $6,1735-1742$. 